\title{
O ENSINO DA FÍSICA DO SOM BASEADO EM INVESTIGAÇÕES ${ }^{1}$
}

\author{
Antônio Tarciso Borges* \\ Bruno Augusto Rodrigues
}

Colégio Técnico, UFMG, Campus Pampulha

31270-901 Belo Horizonte, MG, Brasil

\section{O ENSINO DA FÍSICA DO SOM BASEADO EM INVESTIGAÇÕES}

\section{RESUMO}

Neste trabalho, examinamos as experiências de aprendizagem de um grupo de 9 alunos do $1^{\circ}$ e do $2^{\circ}$ ano do ensino médio em um curso curto sobre a Física do Som em um ambiente de aprendizagem rico em representações e centrado em computador. Os estudantes, divididos em três grupos, estudaram o texto do curso em seu próprio ritmo. Ao longo do estudo os grupos resolviam exercícios de fixação e respondiam a questões abertas. Algumas questões desafiavam os grupos a planejarem atividades de investigação para resolver problemas conceituais. Os dados analisados foram construídos a partir das gravações em vídeo das sessões dos grupos no ambiente de aprendizagem e de testes de conhecimento específico aplicados antes e depois do curso. Os resultados indicam melhoria no desempenho no pós-teste comparado com o pré-teste e na compreensão dos tópicos abordados no curso.

Palavras-chave: Investigações, Ensino de Física, Percepção e Aprendizagem.

\section{ABSTRACT}

In this work, we examine the learning experiences of 9 secondary school students throughout a short course about the physics of sound in a computer-based learning environment rich in representations and focused in student's inquiry. Students worked in group of three people, and each group studied the text in their own pace. At the end of each section of the text, the groups solved exercises and answered open questions. Some of these

\footnotetext{
*Correspondência para A Tarciso Borges, Colégio Técnico UFMG - Setor de Física, Av Antonio Carlos 6627 Campus Pampulha, 31270-901 Belo Horizonte MG

${ }^{1}$ Apoio parcial do $\mathrm{CNPq}$
} 
questions were challenging and asked the groups to plan investigations to solve conceptual problems.

Data analysed were constructed from video recording of the groups' activities and from an open test answered just before and after the course. Pos-test results show significant improvement compared to pre-test. It was also possible to observe development in students' comprehension of the theme.

Key-words: Inquiry-based Learning, Physics Education, Perception and Learning. 


\section{INTRODUÇÃO}

Como resultado de nossa evolução biológica, desenvolvemos um rico e variado sistema perceptual e sensório, com múltiplas modalidades através das quais estabelecemos contato com o mundo à nossa volta (NEISSER, 1976). Isso não é exclusivo da espécie humana e é através desse sistema que somos capazes de perceber regularidades no ambiente à nossa volta e usá-las para dar significado ao que percebemos. É o que nos possibilita desenvolver um variado repertório de experiências fenomênicas, selecionar, recolher e manipular as informações que julgamos relevantes sobre algumas qualidades (visuais, olfativas, sonoras, e outras) que nos permitem perceber e fazer inferências sobre este mundo. O conhecimento construído sobre o mundo dessa forma é fortemente dependente dos contextos e situações com que nos deparamos.

Mas nosso conhecimento sobre o mundo natural não é necessariamente sempre contextualizado. Aqueles indivíduos que conseguem desenvolver conhecimentos e práticas especializados em áreas específicas da ação humana conseguem superar a dependência contextual de seus conhecimentos e saberes. Uma outra forma de ir além da natureza situada de nossa cognição e, ao mesmo tempo, de nossa herança biológica é através da criação de um mundo de objetos de conhecimento, imateriais tal como os objetos descritos pelas teorias e modelos científicos, e ao mesmo tempo, tornando-nos competentes em utilizá-los. Podemos utilizar estes objetos para modelar e simular eventos, processos e fenômenos que experimentamos em nossa interação com o mundo, mesmo que envolvam entidades e processos intangíveis, e produzir, expressar e interpretar representações delas.

Neste trabalho, investigamos a aprendizagem que resulta da participação de um grupo de estudantes em atividades de investigação de fenômenos sonoros que aconteceram em um ambiente de aprendizagem rico em representações. A partir dos resultados discutimos as implicações e a viabilidade de adoção de ambientes dessa natureza no ensino da Física. Argumentamos que a percepção, não apenas a visual, é fundamental na formação e desenvolvimento de nossos conceitos. Descrevemos parte dos instrumentos e atividades que adotamos ao longo da análise do material empírico coletado. Analisamos um episódio em que um grupo de três estudantes discute acerca de questões colocadas pelo texto utilizado no curso e que deu início a uma investigação específica de interesse do grupo. Com isso, esperamos apresentar indícios de como o ambiente de aprendizagem baseado no laboratório escolar que utilizamos permitiu aos alunos se engajarem em uma atividade de investigação memorável e significativa. 
O uso que fazemos de representações não tem qualquer implicação sobre o status ontológico delas, e nem se o nosso processamento mental envolve a manipulação ou codificação interna de símbolos ou não. Embora estejam no centro dos debates sobre a natureza da cognição, as disputas sobre a existência ou não de estruturas representacionais na mente são baseadas em hipóteses ou em crenças sobre nosso funcionamento mental, mas não há evidências fortes em favor de qualquer lado. Queremos marcar nosso uso e entendimento sobre o estatuto das representações de uma forma que contorne os debates estéreis e enviesados sobre o tema na pesquisa em educação em ciências. Nossa perspectiva é pragmática e se apóia no fato incontestável de que nós humanos dispomos de uma capacidade muito desenvolvida para produzir, expressar através de diferentes formas, e interpretar representações e formas simbólicas. Utilizamo-nos dessa habilidade cotidianamente para compreender, interpretar e para comunicar, tornando públicas nossas construções.

\section{O CONHECIMENTO PRÉVIO DOS ALUNOS}

Pesquisas sobre o que crianças e adolescentes acreditam que seja o som, sua produção, suas características, sua transmissão, representações utilizadas e como funciona o processo de audição, foram realizadas por Watts e Russell (1990) e por Asoko, Leach, e Scott (1991), conforme descrição de Driver, Squires, Rushworth \& Robinson (1994). Estas pesquisas sugerem que as crianças e jovens utilizam-se de diferentes modelos para explicar o que é o som, como é produzido, como se propaga.

A pesquisa de Watts e Russel, realizada com 57 crianças, apresenta basicamente três respostas como explicações para a produção do som:

1. Aquelas que envolvem as características físicas do objeto (como o material de que é feito ou a tensão, por exemplo, na película de um tambor).

2. Aquelas que explicam que é a força que o homem utiliza a responsável pela produção de sons (quando, por exemplo, bate-se em um tambor).

3. Aquelas que explicam o som em termos de vibrações.

A pesquisa sugere também que à medida que os entrevistados ficam mais velhos, eles tendem a mudar a forma de explicar a produção de sons em objetos e instrumentos musicais de 1 para 3, passando por 2, como resultado do estudo do tema na escola.

Os resultados referentes à origem do som encontrados por Asoko e equipe foram semelhantes aos encontrados por Watts e Russel, porém observou-se que o objeto de investigação tem influência na escolha do modelo explicativo adotado pelo entrevistado. 
Asoko, Leach e Scott pesquisaram 260 crianças, de 4 a 16 anos de idade, em quatro contextos de produção de som diferentes. No primeiro caso, utilizaram uma corda de violão conectada a um amplificador; no segundo, um brinquedo portando uma buzina de apertar; o terceiro contexto envolvia a produção de som pelo choque de duas pedras e o quarto foi o som proveniente da percussão em um prato metálico, como os de uma bateria.

Eles observaram que o uso do modelo 3, de vibrações, mesmo que não inteiramente consistente, utilizando palavras como balançar, oscilar ou gesticulando com as mãos, foi mais adotado no contexto da corda de violão, com cerca de $80 \%$ das respostas. Porém, poucas crianças relataram a transferência das vibrações para o ar. No contexto da buzina, a maioria dos entrevistados utilizou o modelo 2 para justificar a produção do som e cerca de $40 \%$ dos relatos fizeram referência ao movimento do ar como responsável pela produção do som, sem, no entanto, mencionar a transmissão de vibrações através do ar até nossos ouvidos.

$\mathrm{Na}$ situação do choque entre pedras, a maioria dos pesquisados também utilizou o modelo 2, mas o modelo 1, referente ao material de que são feitas as pedras, também foi utilizado. Não houve explicações envolvendo o ar ou vibrações neste contexto, apenas envolvendo a ação humana e o tipo de rocha utilizada. Isto é, as crianças não possuem uma teoria geral para explicar a produção de som em diferentes contextos e, em alguns casos, recorrem a esquemas muito simples envolvendo apenas os objetos e as ações observados. Os autores recomendam que os materiais curriculares e o professor deveriam planejar e fornecer situações de observação que partam de contextos onde as vibrações são mais evidentes em direção àqueles em que elas são menos evidentes. Eles acreditam que as situações de ensino e aprendizagem baseadas nesta estratégia favorecem a generalização e abstração, contribuindo para ajudar os estudantes na construção de uma teoria geral sobre produção e propagação do som.

\section{O AMBIENTE DE APRENDIZAGEM}

Uma de nossas preocupações está relacionada a como levar as idéias apresentadas na seção introdutória para o currículo. Optamos por fazê-lo através de atividades de ensinoaprendizagem centradas em problemas, conforme sugerido em Borges (2002). As investigações promovem o engajamento dos estudantes com idéias que inspiram suas ações e dão origem a expectativas sobre o que pode ser encontrado, descoberto ou explicado. Num currículo com essa orientação, os alunos devem ser encorajados a explorar como resolver problemas que sejam significativos para eles. 
Formular bons problemas ou encontrar situações interessantes para serem investigadas é difícil, mesmo para quem já tem considerável experiência em fazer isso. Acreditamos que não é razoável esperar que os estudantes consigam propor sozinhos problemas que interessem a eles e que atendam àquilo que o professor deseja que eles aprendam. Também não cremos que existam razões para se trabalhar sempre ou majoritariamente com problemas formulados pelos aprendizes, mesmo que se opte por uma abordagem centrada no estudante. Devemos propor problemas que eles sintam que valem a pena serem enfrentados. Tanto melhor se o problema é encontrado por eles mesmos.

Um problema verdadeiro tem semelhanças com um desafio, e não exercícios rotineiros, que podem ser resolvidos aplicando-se uma regra ou procedimento padrão, como os tradicionais exercícios típicos de fim-de-capítulo. Para encontrar uma solução para um problema, seja ele conceitual ou prático, os alunos terão que conceber, planejar, preparar, executar e interpretar os resultados. Envolvendo-os nessas atividades de solução de verdadeiros problemas, eles mobilizarão e explicitarão seus entendimentos peculiares, suas habilidades investigativas, analíticas e sua imaginação.

Comentando sobre o papel da percepção na construção de conhecimentos e significados, Moreira (2003) aponta que a percepção, a conceitualização e a ação de um sujeito são processos simultâneos e que se desenvolvem de maneira coordenada. A perspectiva que adotamos neste trabalho enfatiza não apenas o que ocorre no plano mental do indivíduo, mas na transação temporal e ativa entre ele e o mundo. Segundo essa perspectiva, um indivíduo interagindo com o mundo percebe uma série de qualidades que determinam que aspectos daquele ambiente são representados e que conceitos são construídos. Esses são formados a partir das experiências que o aparato perceptual torna possíveis. O sujeito é dotado de um sistema sensorial e de uma história pessoal de aprendizagens, um conjunto de atitudes e disposições para perceber o mundo de determinadas formas e dotado de habilidades representacionais, isto é, de produzir e usar artefatos culturais, sociais e cognitivos, que o caracterizam.

Uma vez que o indivíduo transforma seu entendimento em representações e as torna públicas, as qualidades representadas são incorporadas ao ambiente com o qual o sujeito interage. A criação de novas qualidades ambientais, sejam elas comunicadas ou não, torna possível corrigir e revisar os entendimentos que os sujeitos expressam sobre os eventos ou fenômenos com que eles lidam, tornando mais elaborados e sofisticados. Assim, estabelecese um processo de realimentação que influenciará as futuras percepções, ações e 
entendimentos daquela pessoa sobre os objetos, eventos e fenômenos daquela porção do mundo com que ela interage.

Formas particulares de representação tendem a enfatizar qualidades particulares e a privilegiar certas modalidades sensoriais. Como resultado, a variedade de significados que podem ser expressos através de uma forma de representação é limitada. É muito difícil expressar toda a riqueza de detalhes de uma experiência visual, olfativa ou sonora através de proposições faladas ou escritas. O cinema, a fotografia e a televisão podem mostrar belas imagens de uma cena de um barco no mar ou de um piloto de corridas, mas apenas podemos imaginar as vibrações produzidas pelo veículo ou barco no corpo do personagem da cena, ou os odores que são percebidos.

Acreditamos que o ensino de ciências deve ter o compromisso de buscar tornar mais científicos o conhecimento e o pensamento dos estudantes. Com isso queremos enfatizar que precisamos engendrar esforços para que os nossos alunos desenvolvam uma melhor compreensão conceitual das principais idéias e modelos dos cientistas sobre o mundo e os usem de forma adequada dentro de seus limites e possibilidades de desenvolvimento (BORGES \& BORGES; 2001).

Isso não significa, entretanto, que a ciência deva ensinada e aprendida como fato, como um produto acabado. Ao contrário, uma das maneiras de iniciar a aprendizagem de ciência é imitando o fazer da ciência, mas com uma clara orientação de ultrapassar a mera imitação, promovendo o desenvolvimento de práticas de resolução de problemas e de avaliação da qualidade das soluções encontradas. Isso não pode ser conseguido sem o desenvolvimento concomitante de um repertório mais rico de formas discursivas e representacionais, explicativas e causais, e sem o desenvolvimento de uma atitude de busca permanente de respostas para os desafios que encontramos a todo o momento. Acreditamos que é persistindo com essas práticas ao longo de sua escolarização que os alunos desenvolvem gradativamente um arsenal de práticas e estratégias para enfrentar, interpretar e resolver problemas e tornam suas experiências de aprendizagem de ciências na escola mais autênticas e mais próximas do "fazer ciência".

O trabalho que realizamos visava abordar a física do som e foi planejado para possibilitar aos alunos diversas oportunidades de encontrarem questões que merecessem serem investigadas. Nesta perspectiva, o professor adotou a postura de colaborador participante que conferia prioridade à experimentação e debate entre os membros dos grupos, incentivando cada aluno a desenvolver planos para solucionar os problemas encontrados. Ao mesmo tempo, incentivava-os a produzirem suas próprias explicações de 
forma a tornar seus entendimentos correntes da situação-problema mais elaborados e científicos.

Projetamos o ambiente de aprendizagem a partir dessas reflexões. Organizamos um curso curto sobre a física do som, utilizando principalmente atividades investigativas de nível 2. Numa atividade desse nível, um problema inicial é proposto ao grupo. A responsabilidade de fazer o planejamento da investigação, preparar montagens e coletar dados, organizá-los para chegar a resultados e conclusões é do grupo de alunos. O texto utilizado no curso trazia várias questões para discussão e o professor apresentou outras, mas não disse como investigar, que materiais usar e que resultados seriam obtidos.

Ao longo da unidade de estudo, que constituiu o curso, adotamos também atividades de investigação muito simples, que não necessitam do computador ou de qualquer outro recurso tecnológico para serem feitas. Por exemplo, numa das atividades iniciais os alunos eram instruídos para experimentar falar "aaaaaaaa!", mantendo a mão aberta frente à boca ou sobre a garganta de forma a sentir as vibrações do som produzido. Também, utilizando apenas o tato e audição, é possível discutir o que é a caixa de ressonância de alguns instrumentos pedindo aos alunos que falem sem articular a boca e depois observando separadamente as vogais e consoantes.

O objetivo dessas atividades era possibilitar aos estudantes participantes de nosso estudo uma experiência não-mediada pelo sistema conceitual acerca dos fenômenos e conceitos que o texto utilizado apresentava. Tínhamos em mente o fato de que os alunos podem repetir e memorizar com facilidade aquilo que o livro ou professor ensina, sem saber reconhecer o conceito ou o fenômeno na realidade. Por outro lado, eles freqüentemente têm dificuldades em explicitar suas conceitualizações, por não disporem de vocabulário apropriado, como teremos oportunidade de apontar na análise. Acreditamos também ser eficiente ler o texto com a turma e propor pausas para realizar as investigações, colocando os alunos para identificar e resolver problemas, para que, quando estiverem mais acostumados com a idéia de conduzir uma investigação, possamos, então, propor que eles criem experimentos para obter evidências ou para refutar as hipóteses formuladas, ou propostas pelo texto. 


\section{METODOLOGIA}

\section{Participantes}

Os 9 estudantes que se apresentaram voluntariamente para fazer o curso foram divididos em três grupos de três alunos. Eles eram alunos do primeiro ou segundo anos do ensino médio de uma escola do sistema federal de ensino. No resto do trabalho identificamos cada aluno por uma letra, seguida de um número que indica o grupo a que pertencia. Nenhum deles tinha ainda estudado som, já que é um tópico que aqueles alunos estudariam apenas no terceiro ano. Cinco dos participantes eram alunos do 1‥ Ano (A1, B1, C1, D2 e F2)

e os outros estudantes do $2^{\circ}$ ano (E2, G3, H3 e 13). A maioria dos participantes era de rapazes, na realidade, apenas E2 era do sexo feminino, com idades de 16 a 17 anos. O curso durou seis horas, distribuídas em duas sessões de atividades de três horas cada, separadas por um intervalo de uma semana, fora dos horários normais de aula. As atividades desenvolvidas por todos os grupos foram registradas em vídeo para análise posterior.

O estudo foi configurado com a primeira etapa de um experimento de desenho (Brown, 1992). O objetivo do estudo era coletar dados que permitissem avaliar a adequação da unidade desenvolvida para ensinar sobre a física do som para alunos do ensino médio, e a partir destes dados revisar o material para ser utilizado com um número maior de alunos. Por esta razão decidimos trabalhar apenas com alunos voluntários e em períodos fora dos horários normais de aula. O conhecimento dos alunos sobre som foi avaliado através de um teste, aplicado antes do início e ao fim da unidade. O teste apresentava questões envolvendo a compreensão do que é som, como o som é produzido, como se propaga, sobre os conceitos de freqüência, timbre, intensidade e altura de um som. Dois questionários adicionais buscavam informações sobre aprendizagem específica de música, aplicado junto com o pré-teste, e sobre sua avaliação do curso e materiais utilizados, este aplicado junto com o pós-teste. Seis dos nove participantes tinham estudado ou ainda estudavam música (A1, B1, F2, G3, H3 e I3). Completando o questionário, questões acerca da motivação e interesse dos sujeitos em se apresentarem como voluntários para o estudo, fora de seus horários normais de aula, e sobre suas expectativas com relação ao curso.

\section{Procedimentos}

A atividade do tipo investigativa é muito rica porque exige que o aluno ao planejar a sua realização tenha que formular hipóteses, escolher que grandezas medir e como proceder para fazer a medições necessárias. Apenas depois disso, ele estará em condições de testar a 
veracidade das hipóteses que formulou. Tudo isso contribui para uma melhor conceitualização do objeto investigado, que é a essência do desenvolvimento cognitivo. Entretanto, não podemos ignorar o apoio que um bom texto didático possibilita e as vantagens imediatas que exercícios e questões apresentam, justamente na fixação de idéias e conceitos, o que contribui para elevar o nível de uma discussão em grupo.

Neste estudo fez-se a opção por usar um texto paradidático e interdisciplinar, que relaciona o som à fisiologia do corpo humano capaz de percebê-lo, e que busca enfatizar os conceitos e as relações matemáticas entre eles através uma abordagem qualitativa e conceitual. É um texto destinado a crianças, mas ainda assim dá uma noção bastante completa dos processos da fala e da audição, ressaltando aspectos físicos essenciais à sua compreensão. A função do texto era a de servir de apoio para que os estudantes pudessem discutir as questões propostas, indo além daquilo que o livro apresentava.

Antes que as equipes começassem o trabalho de planejamento e investigação, elas foram estimuladas a discutir com o professor o que chamamos de regras para o trabalho em grupo. Algumas normas simples como: procurar definir as variáveis a serem investigadas e ouvir os colegas. Tais normas logo foram postas em prática, quando em seguida, verificando como funcionava o programa de coleta automática de dados usando um sensor de sons, os participantes fizeram uma análise de um tom de voz produzido por um dos alunos. Eles aprenderam como proceder para coletar e exibir os dados de várias formas.

\section{RESULTADOS E DISCUSSÕES}

\section{Pré e pós-teste}

Apresentamos inicialmente os resultados dos nove participantes nos testes aplicados no início e ao final da unidade de ensino. Prosseguiremos depois analisando em detalhes uma investigação que surgiu das discussões do grupo 1. Em conformidade com a natureza do estudo e o número limitado de participantes, optamos por utilizar os mesmos itens nos dois testes. Isso garante que os resultados possam ser comparáveis, embora possibilite a ocorrência de efeitos indesejáveis. Como estávamos desenvolvendo uma unidade de ensino e não havia um grupo de itens de testes validados para aplicação, esta opção pareceu mais sensata. Somado ao pequeno número de participantes, estes aspectos recomendam cautela quanto à generalização dos resultados dos testes.

Inserir Figura 1 nesta altura do texto

O teste consistiu de um conjunto de oito questões abertas, sem limite de tempo para respondê-las. Um conjunto de critérios foi estabelecido para a correção dos testes. $\bigcirc$ valor 
máximo atribuído a cada item foi 1,0. As questões e os critérios podem ser encontrados no apêndice 1. Os critérios são visavam diferenciar respostas corretas e completas, daquelas corretas e incompletas, ou incorretas, de forma a valorizar aspectos particulares das respostas dos participantes. Os testes foram corrigidos independentemente por dois professores e as diferenças resolvidas.

A figura 1 compara o desempenho dos alunos em ambos os testes. Nas questões 1 , 6, 7 e 8 os participantes mostraram-se muito mais precisos em suas respostas no teste final comparado com o teste inicial, com exceção dos alunos I3 e G3. São questões que tratam de distinção entre som alto e baixo (1), a noção de 'volume do som' (6), a noção de afinação de um instrumento (7) e a necessidade de meio material para a propagação do som (8). Aparentemente, em algumas delas, como é o caso de (1) e (6), as respostas iniciais eram derivadas do uso cotidiano dos termos, sem tradução em termos de conceitos científicos de freqüência e amplitude ou intensidade.

Nas outras questões já havia um entendimento inicial insatisfatório e os alunos melhoraram sensivelmente ao longo do curso. O desempenho dos alunos ao responder à questão 3 é ligeiramente inferior ao do pós-teste. A questão pergunta se o participante conseguiria reconhecer uma mesma seqüência de notas tocadas num violão ou num piano. Os alunos em geral respondem que sim, justificando que apesar do timbre diferente, as freqüências tocadas seriam iguais. No pós-teste, eles mantêm a mesma postura geral, ou procuram ser mais precisos, mas referem-se à sua pouca habilidade em reconhecer notas musicais. A questão 5 pergunta-lhes sobre o que os permite reconhecer as vozes de seus amigos e amigas. O desempenho em ambos os testes é praticamente o mesmo, mas as respostas são muito precisas, em ambos os casos.

O grupo 2, com pior desempenho no teste inicial, é o que apresenta maiores ganhos em desempenho. O grupo 1 apresenta ganhos moderados, e o grupo 3 praticamente permanece da mesma forma. Neste último grupo, os estudantes G3 e I3 que tinham dado respostas muito precisas e completas no pré-teste mostram-se menos precisos no pós-teste. Suas respostas ainda são muito boas de modo geral, embora mais concisas. Acreditamos que os resultados do grupo 3 no pós-teste possam ser explicados pelo fato de que o teste não apresentou novidades e desafios para o grupo.

Este foi um resultado que não esperávamos, especialmente considerando que G3 e I3 foram os dois estudantes que tiveram os melhores desempenhos no pré-teste. Não era nosso propósito discutir em detalhe as razões para possíveis variações no desempenho dos participantes na primeira oferta do curso, em vista da opção de trabalhar com uma 
metodologia de desenvolvimento Brown (1992). Flutuações dessa ordem são normais em situações de avaliação. Elas podem ter sido produzidas por muitos fatores, entre os quais imperfeições no teste e o nível de engajamento dos alunos. Sobre isso, gostaríamos de destacar que de modo geral, as respostas dos estudantes G3 e I3 aos itens do pós-teste são mais concisas do que no pré-teste ${ }^{1}$. A resposta do estudante G3 para o item 1 do pós-teste é correta, mas incompleta. Já o desempenho do estudante 13 foi afetado principalmente por sua resposta ao item 3.

Nas questões 1, 6, 7 e 8 os participantes do curso obtiveram ganhos em desempenho no pós-teste de $20 \%, 40 \%, 33 \%$ e $22 \%$, respectivamente. Abaixo temos alguns exemplos de respostas a estas questões em ambos os testes.

\section{Questão 1}

H3, antes: Um som alto é uma onda sonora de grande amplitude e o som baixo é uma onda sonora de pequena amplitude.

H3, depois: Um som alto é aquele que tem uma alta freqüência e um som baixo é aquele que tem uma baixa freqüência.

\section{Questão 6}

F2, antes: É a "altura" que ele atinge.

F2, depois: $O$ volume do som é a amplitude do som, que é a altura da onda sonora que na verdade é a sua intensidade.

\section{Questão 7}

E2, antes: Não sei.

E2, depois: É colocar as ondas sonoras de cada nota na mesma freqüência que outro instrumento ou da voz da pessoa. Os dois devem ter a mesma freqüência.

\section{Questão 8}

A1, antes: Por causa da forma da onda, quando não se tem um meio como o ar, ou o carbono, ele não se propaga, se o George Lucas fosse respeitar a física o Star Wars não teria som porque o som não se propaga no vácuo.

A1, depois: Sim, porque ele vai passando sua vibração pra frente, os meios mais fáceis de se conduzir o som é pelos gases. 


\section{O caso do grupo 1}

Analisamos a seguir um episódio envolvendo o grupo 1 ( $\mathrm{A} 1, \mathrm{~B} 1$ e $\mathrm{C} 1)$ que é ilustrativo da aprendizagem promovida por um ambiente como esse e das tentativas dos alunos em construir significados para aquilo que lêem, discutem e observam, que não é capturada pelos testes. O grupo 1 é o grupo intermediário, tanto em termos de desempenho no teste inicial, quanto em termos de aprendizagem medida pela comparação entre os resultados dos membros do grupo no pré- e o pós-teste. Eles eram, à época do estudo, alunos do primeiro ano. Dois deles estudavam música fora da escola, mas não tinham estudado a física do som, como nenhum dos outros participantes. Depois de ler o texto, "Som", que descrevia a Física do som e a fisiologia do corpo humano capaz de produzi-lo e captá-lo, os três alunos começaram a ler e responder às questões sobre o texto. Selecionamos para análise um episódio envolvendo o grupo, cujo início ocorreu quando o estudante B1 chegou à questão 2 transcrita abaixo e dirigiu uma pergunta ao professor $(P)$ :

Questão 2 - Sabe-se que todo som é proveniente de vibrações da fonte sonora que colocam o ar a vibrar. Sabe-se também que a voz feminina é, em geral, mais aguda do que a masculina, que é grave. Então escreva com suas palavras as possíveis razões para este fato, ou o que você acha que seria um argumento científico que justifica esta diferença entre as vozes feminina e masculina.

B1: Aqui, para saber a diferença de uma... Por exemplo, eu estou com uma corda e quanto mais esticada ela estiver mais agudo vai ser o som não é?

$P$ : Esta resposta não tem no texto?

B1: É, eu não estou achando, mas só para confirmar.

A1: Aqui na página 7, "Se uma coisa vibra dezenas de vezes por segundo, nós ouvimos um tom baixo. Se ela vibra muitas centenas ou milhares de vezes por segundo, um tom alto vai soar".

B1: Tá, mas ai está escrito alto e baixo?

A1: Alto é agudo e baixo é grave.

B1: Tá! [Ele gesticula a cabeça demonstrando insatisfação], mas o negócio é que não está especificando.

A1: Você pode ver aqui, assim, olhe [o aluno A1 pega o fio do sensor de som, segura-o com uma mão em cada ponta, esticando-o. Depois com um dedão tenta percutir o fio].

B1: Tem uma parte do texto que está especificando, mas eu não lembro onde está. 
O aluno B1 dirige-se ao professor desejando apenas confirmar a informação que tinha lido no texto, mas pode-se perceber que ele não tem confiança na distinção entre os conceitos de som agudo e som grave ou alto e baixo. Este aluno até o momento tinha recebido informações apenas através do texto e isto pode ser inferido de sua resposta à pergunta 1 do teste sobre o que é um som alto: "As partículas do ar batendo uma nas outras com muita energia ou pouca". Ele confunde altura do som com intensidade. Seu companheiro A procurou representar o conceito de outra forma, usando o fato de que uma corda mais tensionada emite sons mais agudos quando percutida. Entretanto, o fio que ele utilizou não era apropriado para reproduzir o fenômeno, e B ficou insatisfeito.

Os alunos encerraram a discussão, mesmo sem ter ainda uma compreensão clara acerca da questão. Embora B1 parecesse estar visivelmente insatisfeito, eles decidiram ir em frente, para a questão 3 .

Questão 3- Imagine duas cordas iguais presas a um violão, mas uma está mais esticada do que a outra. Explique qual será a diferença entre o som produzido pelas duas cordas se postas a vibrar de forma semelhante.

Neste ponto da atividade, o professor aproveita a oportunidade para trazê-los de volta à discussão daquilo que era motivo de dúvida:

$P$ : A gente podia tentar confirmar a dúvida de $B$, vamos?

C1 e B1: Vamos.

P: Então tá, este aqui é o monocórdio e este nome é porque ele só tem uma corda. Mas como vamos fazer? Qual o procedimento que vamos adotar para poder ver a diferença?

C1: Batucar a corda com esta tensão e depois com outra.

Após a introdução de um dispositivo apropriado para a produção do fenômeno (o monocórdio), eles decidem como seria feita a investigação. Os membros do grupo decidem usar o sensor para coletar dados em sua investigação ${ }^{2}$. Optaram por coletar o som natural do monocórdio, para depois, aumentar a tensão na corda, coletar de novo o som e sobrepor os gráficos em cores distintas, utilizando o software de exibição do sistema de coleta automática de dados. Discutem, após a intervenção do professor para explicitar o plano deles, que o comprimento da corda deveria ser mantido constante. O que se segue é uma seqüência de etapas de preparação do sistema de coleta de dados, coleta e leitura indireta da freqüência na tela.

$\mathrm{Na}$ verdade, eles fazem leituras das vibrações sonoras num certo intervalo de tempo, que são tratadas pelo programa que gerencia a coleta de dados e são exibidas na tela do 
computador. Várias grandezas físicas são passíveis de serem medidas: freqüência do tom fundamental e sobretons, períodos associados, amplitude. Precisam seguir vários procedimentos para ajustar as escalas nas duas janelas de exibição que selecionaram. As duas janelas exibem os resultados das duas coletas: em uma delas eles podem medir o período de uma vibração e determinar a freqüência do som, na outra podem superpor os dois gráficos para compará-los (um gráfico com linha contínua e o gráfico com linha tracejada, como mostra a figura 2).

Eles se encontram absorvidos e engajados em resolver o problema, discutindo freqüentemente os detalhes e refazendo várias vezes as coletas de dados. Há uma clara mudança de orientação: o problema deles passou a ser produzir evidências sobre a relação entre a tensão na corda e a freqüência do som produzido, usando ferramentas específicas. A questão inicial apresentada pelo texto, que envolvia a conceitualização de som agudo e som grave, e tons alto e baixo, tornou-se secundária para eles. Todo o desenrolar da atividade é um exemplo claro de que tinham um novo problema, formulado a partir de suas discussões e que a percepção, a conceitualização e a ação de um sujeito são processos simultâneos e que se desenvolvem de maneira coordenada (MOREIRA. 2003).

C1: Acho melhor a gente fazer assim. [Enquanto ajustavam a trava que regularia a tensão na corda]

B1: Ou assim, deixa eu pegar aqui.

P: Vamos ver como fica a coleta?

C1: Acho que não deu em nada.

P: Pode fazer de novo.

B1: Qual que vai pegar primeiro? [O som de maior ou menor tensão na corda?]

C1: A preta, não é?[Refere-se à cor da linha do gráfico]

A1: Toca. [Dizendo que estava pronto para coletar]

P: Deu certo?

C1: Começa de novo. Dá um new [Abrir uma nova janela] Coloca em 1000 a taxa de amostragem.

A1: Menos pontos [Fala sobre duração da coleta].

C1: Não, mais pontos... 10 é pouco. Pronto? Pode ir?

A1: Aí.

P: Tem que salvar esta antes de coletar de novo.

A1: Tá. 
A investigação que utiliza sensores automáticos de coleta de dados e produz gráficos em tempo real permite otimizar o tempo e corrigir falhas no planejamento inicial. Tal gráfico é um outro tipo de representação que destaca características particulares do fenômeno, contribuindo para a conceitualização dos alunos sobre o que é um ciclo, período, freqüência, amplitude e forma de onda. Percebe-se que todos os membros do grupo possuem pleno conhecimento do objetivo da investigação que estão realizando e de como realizá-la. Não foi solicitado que explicitassem as suas hipóteses sobre o fenômeno. Mas eles as tinham, como indicam os seus julgamentos sobre a adequação, ou não, dos seus resultados experimentais e pelas decisões que tomam ao longo da atividade, como estimar que valor da taxa de amostragem seria adequado. Apesar de ser essa a primeira vez que usavam o sistema de coleta de dados sozinhos, eles se sentiam à vontade.

P: Como a gente pode ver então? [As diferenças entre os gráficos continuo e tracejado na figura 2, que aparecem coloridos na tela do computador que usavam]

A1: É, não deu como você falou não.

$P$ : É, mas um outro jeito de fazer a análise comparativa seria como?[Pergunta como eles podem comparar as freqüências]

A1: Fazendo zoom.

P: Nesse zoom que você deu ai, dá?

C1: Se você visualizar lá.

P: Como?

C1: Uma freqüência maior, uma menor...

P: Mas como é que você vê?

C1: Vendo se tá maior ou menor [abrindo os dedos para sinalizar uma distância verticalmente, referindo à amplitude]

B1: Não, é vendo se tem menos espaço entre... [com o dedo faz um sobe-e-desce imitando a forma do gráfico senoidal, referindo-se ao número de ciclos exibidos na janela gráfica]

C1: É, também. A freqüência e o comprimento de onda.

$P$ : Você está falando que mais freqüente vai ter... [e gesticula igual a B com o dedo]

B1: É vai dar mais... [repete o mesmo gesto, indicando que se a freqüência for maior, a janela exibirá um número maior de ciclos]

C1: É e em menos tempo.

$B 1: E ́$.

$P$ : Contando os vales no gráfico? [refere-se ao que a figura 2 exibe]

B1 e C1: É. [respondem ao mesmo tempo]. 
P: Tem que mostrar as duas, a contínua e a tracejada e ai é só contar os vales.

C1: Hum, hum!

$P$ : E de ouvido? Vocês percebem a diferença?

A1: Sim, fica mais agudo.

Percebe-se, no último trecho do diálogo, que faltam aos estudantes os termos apropriados para se referir aos conceitos, mas que todos eles desenvolveram um entendimento final correto do que deveriam encontrar. O entendimento torna-se possível pelo uso de gestos para sinalizar sobre o que estavam falando. O estudante $\mathrm{C} 1$ referia-se inicialmente à amplitude das oscilações, como indicador de som alto ou som baixo. B1 não concorda, e gesticula reproduzindo no ar com o dedo a forma de onda, indicando que no som alto os vales, e também os picos, estão mais próximos entre si. Sua compreensão é correta, apontando que nos sons altos o período é menor e a freqüência maior. O estudante $\mathrm{C} 1$ concorda e chama de "comprimento de onda" a distância horizontal entre dois máximos consecutivos. Essa é uma confusão freqüente, que decorre da não-diferenciação entre duas formas de representação muito comuns: o gráfico da amplitude instantânea em função do tempo, e a representação esquemática do 'perfil' da onda no espaço. Por fim, C1 se convence do ponto de vista de B1. Finalmente, em resposta à provocação do professor, A1 demonstra um claro entendimento da associação de sua percepção de sons graves e agudos e freqüência.

No início, o estudante $\mathrm{A} 1$ fala para o professor que a análise de Fourier que ele tinha feito do som não deu certo. Porém, este era um recurso alternativo que o professor havia ensinado, mas que não era adequado para a análise dos gráficos sobrepostos. Seu procedimento de contar o número de ciclos, contando os vales ou picos presentes num certo intervalo de tempo era mais simples e direto. Esta análise dos gráficos, a partir da ampliação (zoom), ajudou C1 a esclarecer a confusão que fazia entre os conceitos de comprimento de onda e amplitude. Por fim, o professor chama a atenção para o fato de que qualitativamente não é preciso contar o número de ciclos para chegar a uma conclusão, basta utilizar o sensor auditivo natural que possuímos. 


\section{Opinião dos alunos}

Ao participarem desse curso como voluntários, os alunos estavam interessados em saber mais sobre a física do som (cinco das nove respostas). Todos relataram que suas expectativas foram atendidas. Três deles espontaneamente disseram que retornaram para 0 segundo dia de trabalho porque o primeiro tinha sido interessante. Perguntados se o curso atendeu às suas expectativas, B1 respondeu "Sim, aprendi várias coisas que desconhecia", enquanto que o aluno D2 respondeu que "Sim, pois pude aprender muitas coisas novas e completar as coisas que já sabia, mas que não estavam bem explicadas".

Todos eles definiram o material como interessante e acessível, e relataram que a parte escrita da apostila (as atividades abertas de nível 2) foi bastante esclarecedora, mostrando que não só atividades de demonstração, mas também de investigação são eficientes para o entendimento de conceitos científicos. Por fim relataram que, dos conteúdos abordados, o mais interessante foi sobre a fisiologia do corpo humano capaz de detectar o som.

\section{CONCLUSÕES}

O ensino da física do som adotando um texto introdutório com atividades de resolução de problemas, conceituais e práticos, mostrou-se produtivo, permitindo aos estudantes experiências de aprendizagem ricas. Os testes por mais bem construídos e detalhados não conseguem capturar toda a experiência que os estudantes vivenciaram, como ilustrado no caso do grupo 1. As atividades realizadas contribuíram para a re-elaboração dos conceitos básicos tratados e para a compreensão das formas como eles são exibidos e representados. Todos os participantes julgaram o material acessível, esclarecedor e interessante. Alguns deles tinham interesse pessoal no tema que o motivaram a estudá-lo fora da escola. A análise do pré-teste possibilitou inferir quais eram os conceitos espontâneos que os alunos apresentavam. Permitiu identificar também que alunos já tinham conhecimentos mais desenvolvidos sobre conteúdo a ser abordado. Ela indica também que os estudantes que mais se beneficiaram do curso foram aqueles que tinham pouco conhecimento conceitual sobre o tema. Por outro lado, dois dos estudantes que tiveram desempenho muito bom no pré-teste, não mostraram a mesma performance no pós-teste. Este resultado, embora possa ter sido produzido por características do teste e do envolvimento dos estudantes, é realçado pelo pequeno número de participantes no estudo. 
Independente disso, é um aspecto que merece ser examinado com cuidado em aplicações futuras do curso.

O episódio analisado apresenta indícios da riqueza das discussões no grupo e da construção coletiva de significados, apesar de ser uma atividade muito curta, com apenas dois encontros e a primeira oportunidade que os participantes tiveram de usar sensores e 0 sistema automático de coleta de dados. Acreditamos ter apresentado evidências de que em atividades planejadas para permitir um tempo maior de exploração aos alunos poderão produzir experiências mais significativas de aprendizagem.

A análise do episódio envolvendo o grupo 1 é indicadora da capacidade dos estudantes do grupo em se engajarem na investigação de problemas que eles mesmos formularam, a partir de um problema inicial proposto pelo texto utilizado. No episódio analisado fica claro que os estudantes do grupo tinham clareza quanto aos objetivos de sua investigação e dos procedimentos que deveriam adotar para conseguir responder à questão que se colocavam. Não foi solicitado que explicitassem as suas hipóteses sobre o fenômeno, mas a maneira como avaliam a adequação dos seus procedimentos, os resultados intermediários e tomam decisões, indicam que eles as tinham. 


\section{Referências Bibliográficas}

BORGES, A. T.; BORGES, O. N.; VAZ, A. M. (2001a). Planejamento da Solução de um Problema. Anais do III Encontro Nacional de Pesquisa em Educação em Ciências. Porto Alegre, RS:ABRAPEC, 2001. v. 1, p. 1-12.

BORGES, A. T. Novos Rumos Para o laboratório Escolar de Ciências. Caderno Brasileiro de Ensino de Física, Florianópolis, SC, v. 19, n. 3, p. 291-313, 2002.

BORGES, A. T. e BORGES, O. N. (2001). INOVAR - Currículos: desenvolvendo o pensar e o pensamento científicos. Projeto integrado de pesquisa apoiado pelo CNPq.

BROWN, A. L. (1992). Design Experiments: Theoretical and methodological challenges in creating complex interventions in classroom settings. The Journal of the Learning Sciences, 2, 141-178.Mahwah, NJ: Lawrence Erlbaum.

DRIVER R., SQUIRES A., RUSHWORTH P., ROBINSON V. W. (1994). Making Sense of Secondary Science: Research into children's ideas. London: Routledge.

GARDNER, H. (1985). The mind's new science: A history of cognitive revolution. New York: Basic Books.

GREENO, J. (1989). Perspectives on thinking. American Psycologist, 44 (2), 134-141.

MOREIRA, A. F. (2003). Práticas de interpretação em ambientes de aprendizagem de Física. Tese de Doutorado. Faculdade de Educação da UFMG. Belo Horizonte, MG, 168 p.

NEISSER, U. (1976). Cognition and reality: Principles and implications of cognitive psychology. San Francisco: Freeman. 
Apêndice 1 - Questionário e Grade de correção

\begin{tabular}{|c|c|c|}
\hline & \multicolumn{2}{|l|}{ Critério de avaliação das respostas dos itens (o uso correto dos conceitos de) } \\
\hline \multirow{4}{*}{1} & O que você acha que é um som alto? E um som baixo? Explique. & Valor \\
\hline & frequência & 0,6 \\
\hline & ciclos por segundo & 0,2 \\
\hline & agudo, grave ou comprimento de onda & 0,2 \\
\hline \multirow{4}{*}{2} & $\begin{array}{l}\text { É possível que um som seja tão alto que não possa ser ouvido? Explique sua } \\
\text { resposta. }\end{array}$ & \\
\hline & respondendo sim & 0,6 \\
\hline & faixa de freqüência ou percepção limitada da capacidade auditiva & 0,2 \\
\hline & referindo-se aos cílios localizados no Órgão de Corti & 0,2 \\
\hline \multirow{4}{*}{3} & $\begin{array}{l}\text { Se dois músicos tocarem a mesma seqüência de notas, porém um na flauta e } \\
\text { outro no violão, você seria capaz de dizer se eles realmente tocaram a mesma } \\
\text { seqüência de notas? Explique. }\end{array}$ & \\
\hline & respondendo sim & 0,6 \\
\hline & mesma freqüência & 0,3 \\
\hline & mesmas notas, harmonia ou silêncio & 0,1 \\
\hline \multirow{4}{*}{4} & $\begin{array}{l}\text { Consegue dizer de ouvido quando uma música foi tocada no violão ou no piano? } \\
\text { Em caso afirmativo explique o que existe em cada instrumento que lhe permite } \\
\text { fazer esta distinção. }\end{array}$ & \\
\hline & respondendo sim & 0,4 \\
\hline & explicando em termos de timbre & 0,4 \\
\hline & mencionando forma da onda, harmônicos e sobretons & 0,2 \\
\hline \multirow{4}{*}{5} & $\begin{array}{l}\text { Você consegue reconhecer seus amigos/amigas pela voz? O que existe na voz } \\
\text { que permite isso? }\end{array}$ & \\
\hline & respondendo sim & 0,5 \\
\hline & explicando em termos de timbre & 0,4 \\
\hline & forma da onda, nota ou freqüência & 0,1 \\
\hline \multirow{4}{*}{6} & O que você acha que é o volume de um som? Explique. & \\
\hline & uso correto dos conceitos de amplitude ou intensidade & 0,6 \\
\hline & uso sem explicação de intensidade ou amplitude & 0,2 \\
\hline & escrevendo sobre energia para deslocar o ar, potência, compressão e rarefação & 0,2 \\
\hline
\end{tabular}




\begin{tabular}{|l|l|c|}
7 & O que quer dizer afinar um instrumento? & \\
\cline { 2 - 3 } & mencionar freqüências bem definidas & 0,7 \\
\cline { 2 - 3 } & em relação a um padrão de freqüência & 0,3 \\
\hline \multirow{2}{*}{8} & O som precisa de um meio material para se propagar. Explique esta afirmativa. & \\
\cline { 2 - 3 } & respondendo sim & 0,5 \\
\cline { 2 - 3 } & mencionando características de ondas mecânicas & 0,3 \\
\cline { 2 - 3 } & vibrações de matéria, transmissão de vibração, compressão e rarefação & 0,2 \\
\hline
\end{tabular}




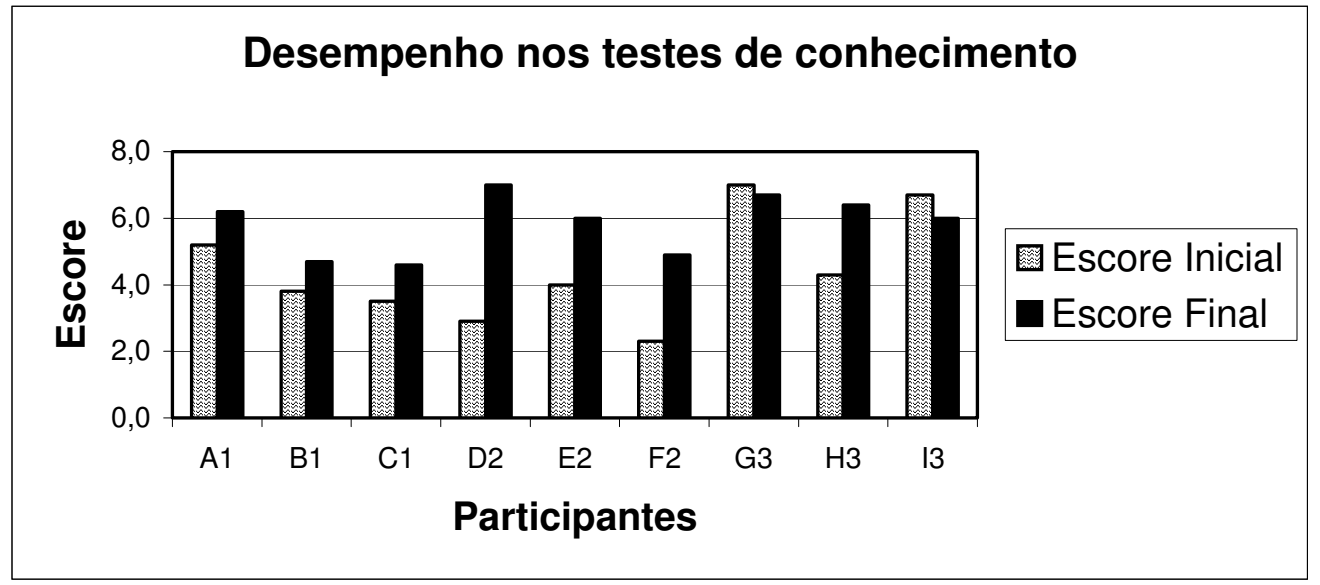

Figura 1 - Desempenho dos alunos no pré- e pós-teste

\begin{tabular}{lllllllllll} 
Aluno & & A1 & B1 & C1 & D2 & E2 & F2 & G3 & H3 & I3 \\
\hline Desempenho & Pré- & $\mathbf{5 , 2}$ & $\mathbf{3 , 8}$ & $\mathbf{3 , 5}$ & $\mathbf{2 , 9}$ & $\mathbf{4 , 0}$ & $\mathbf{2 , 3}$ & $\mathbf{7 , 0}$ & $\mathbf{4 , 3}$ & $\mathbf{6 , 7}$ \\
Desempenho & Pós- & 6,2 & 4,7 & 4,6 & 7,0 & 6,0 & 4,9 & 6,7 & 6,4 & 6,0 \\
\hline
\end{tabular}

Tabela 1- Resultados individuais no pré-teste e pós-teste 


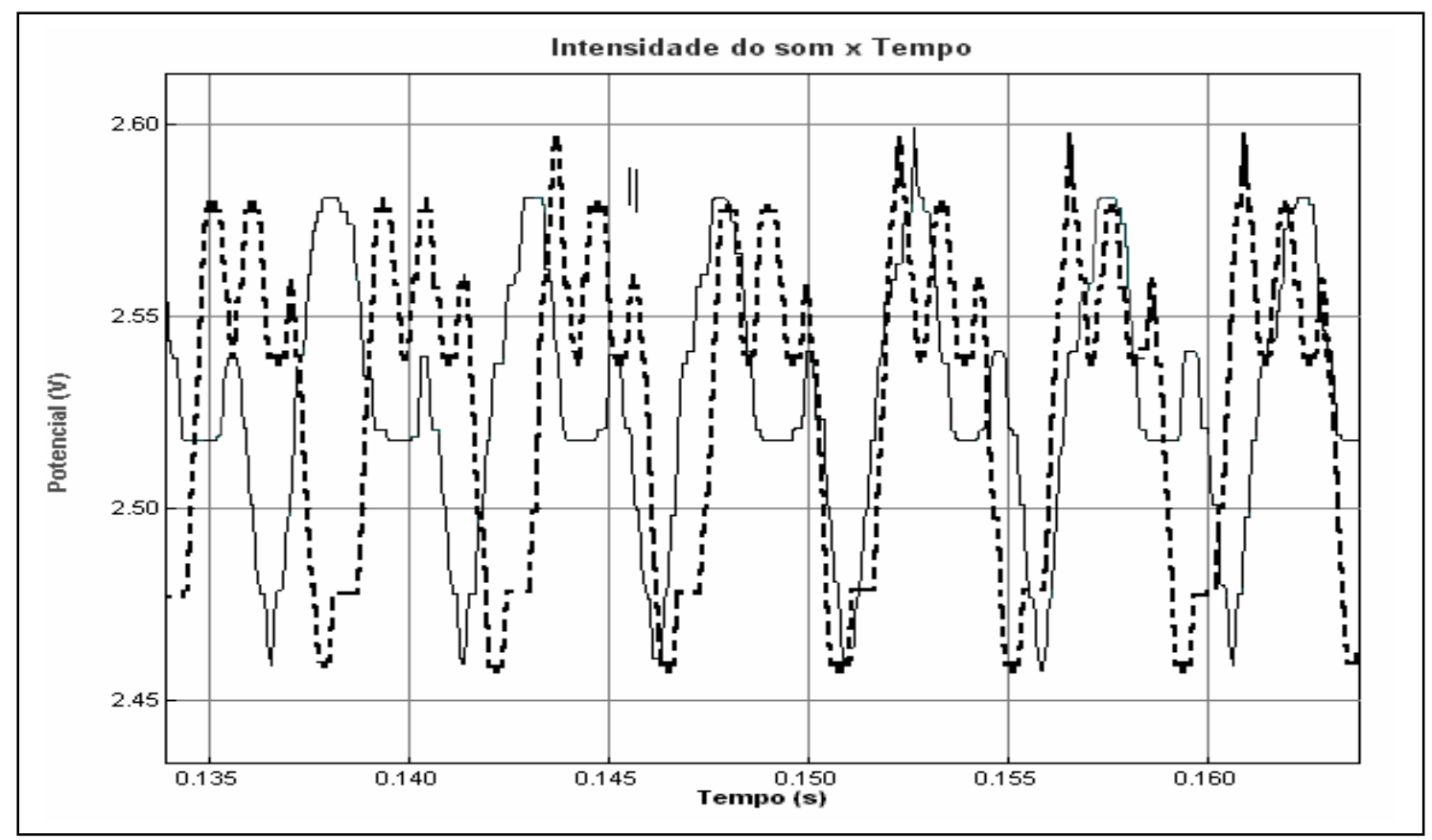

Figura 2 - Vibrações produzidas pelo monocórdio submetido a dois valores de tensão mecânica.

1 Agradecemos a leitura cuidadosa de um dos árbitros, que chamou nossa atenção para a necessidade de explicação dessa 'anomalia' e das conseqüências sobre a efetividade e avaliação da prática como um todo. Concordamos em parte com a observação. O resultado desses dois estudantes (ou seja, de $22 \%$ dos participantes) coloca em questão os instrumentos de avaliação do conhecimento que utilizamos e sua forma de aplicação. As variações são, no entanto, muito pequenas, para serem consideradas anomalias. Ao contrário, flutuações dessa ordem são muito comuns em avaliações de aprendizagem. Do ponto de vista do desenvolvimento do material, o fato de que os outros 7 estudantes, mesmo aqueles com desempenho muito fracos no pré-teste, apresentaram rendimento melhor no pós-teste é mais importante e informativo.

${ }^{2}$ Num momento anterior do curso, o professor apresentou aos estudantes um sistema para coleta automática de grandezas sonoras. O sistema foi usado para a visualização de formas de onda, mas permite a medição de várias grandezas, como período, amplitude e frequiência. Os dados de cada amostragem podem ser armazenados na memória, para análise posterior. $\mathrm{O}$ sistema usado consistia de um sensor sonoro, um dispositivo de interfaceamento, que converte o sinal coletado da forma analógica para digital e entra com ele computador. Completa o sistema um programa que monitoramento que controla os parâmetros da amostragem e que possibilita a exibição dos dados, na forma de tabelas e gráficos. $\mathrm{O}$ software funciona com sistema operacional Windows e é de operação intuitiva e simples. O sistema todo funciona como um osciloscópio, mas é mais simples e flexível. O sistema permite repetir medições acionando uma única tecla, permite ao usuário imprimir as informações exibidas na tela, escolher cores e escalas, definir nomes das variáveis. 